\title{
Estudos dos constituintes químicos e atividade antibacteriana do óleo essencial de Lippia gracilis a Xanthomonas campestris pv. viticola "in vitro"
}

\author{
Morgana Mateus Santos; Ana Rosa Peixoto ${ }^{1}$; Esmailly de Sousa Pessoa ${ }^{1}$; Helena Brandão dos Santos Nepa ${ }^{1}$; \\ Cristiane Domingos da Paz ${ }^{1}$; Ana Valéria Vieira de Souza ${ }^{2}$.
}

\begin{abstract}
${ }^{1}$ Departamento de Tecnologia e Ciências Sociais, Universidade do Estado da Bahia, CEP 48900-000, Juazeiro, BA. ${ }^{2}$ EMBRAPA- Semiárido, Cx. Postal 23, CEP 56302-970, Petrolina, PE.

Autor para correspondência:Morgana Mateus Santos (morganamateuss@hotmail.com)

Data de chegada: 17/12/2013. Aceito para publicação em: 28/07/2014.
\end{abstract}

$10.1590 / 0100-5405 / 1958$

\section{RESUMO}

Santos, M.M.; Peixoto, A.R.; Pessoa, E.S.; Nepa, H.B.S.; Paz, C.D.; Souza, A.V.V.. Estudos dos constituintes químicos e atividade antibacteriana do óleo essencial de Lippia gracilis a Xanthomonas campestris pv. viticola "in vitro". Summa Phytopathologica, v.40, n.3, p.277-280, 2014.

Este trabalho foi realizado com o objetivo de estudar a eficácia de óleos essenciais de Lippia gracilis, no crescimento in vitro de Xcv. Foram utilizados oito óleos extraídos de L. gracilis, obtidos de diferentes manejos de cultivo, em três dosagens diferentes $(200 ; 250$ e $300 \mu$ L.L.-1 $)$, testemunha com o oxicloreto de cobre (controle padrão) e a testemunha absoluta. A suscetibilidade do isolado Xcv3 aos óleos testados foi avaliada na primeira etapa pela presença e ausência do crescimento bacteriano e, na segunda etapa, pela porcentagem de inibição do crescimento bacteriano. A análise da composição química dos óleos essenciais extraídos de L.gracilis, mostrou, o carvacrol (73,9 a 77\%) como composto majoritário e o timol (4,9 a 10,3\%). Os óleos referentes aos tratamentos 01,06 e 07 foram os que proporcionaram maiores porcentagens de inibição no crescimento bacteriano de Xcv: $94,75 \%, 96,50 \%$ e $94,02 \%$, respectivamente, sendo superiores ao oxicloreto de cobre $(49,6 \%)$.

Palavras-chave adicionais: timol, carvacrol, ação antimicrobiana, oxicloreto de cobre, cancro bacteriano.

\section{ABSTRACT}

Santos, M.M.; Peixoto, A.R.; Pessoa, E.S.; Nepa, H.B.S.; Paz, C.D.; Souza, A.V.V.. Studies of chemical compounds and antibacterial activity of the essential oil from Lippia gracilis against Xanthomonas campestris pv. viticola "in vitro". Summa Phytopathologica, v.40, n.3, p.277$280,2014$.

This study aimed to verify the efficacy of essential oils from Lippia gracilis on the in vitro growth of Xcv. Eight oils were extracted from L. gracilis and obtained from different cultivation management types at three different doses (200, 250 and $\left.300 \mu \mathrm{L} . \mathrm{L}^{-1}\right)$, control using copper oxychloride (standard control) and absolute control. The susceptibility of the isolate $\mathrm{Xcv} 3$ to the tested oils was evaluated in the first step based on the presence and absence of bacterial growth, and in the second step based on the percentage of bacterial growth inhibition. Analysis of the chemical composition of essential oils extracted from L. gracilis showed carvacrol $(73.9$ to $77 \%)$ as the major compound, and thymol (4.9 to $10.3 \%$ ). The oils corresponding to treatments 01,06 and 07 provided the largest percentages of Xcv bacterial growth inhibition: $94.75 \%, 96.50 \%$ and $94.02 \%$, respectively, greater than that of copper oxychloride (49.6\%).

Additional keywords: thymol, carvacrol, antimicrobial action, copper oxychloride, grapevine canker disease

Dentre as doenças que ocorrem em videira no Submédio do Vale do São Francisco, destaca-se o cancro bacteriano, causado por Xanthomonas campestris pv. viticola (Nayudu) Dye (Xcv). O controle da doença é considerado difícil e o uso de produtos cúpricos nem sempre é efetivo, devido à existência de isolados de Xcv que apresentam tolerância a esses compostos. Um dos enfoques da agricultura moderna é o controle alternativo de doenças, o qual inclui o controle biológico e o uso de óleos essenciais com atividade antimicrobiana.

Vários trabalhos vêm sendo realizados buscando demonstrar o potencial da utilização desses óleos no controle de fitopatógenos. Como exemplo o alecrim da chapada, (Lippia gracillis Schauer) é uma planta rica em óleo essencial, constituído pelo timol (10\%) e pelo carvacrol $(41,7 \%)$, e que apresenta atividade antimicrobiana (2).

Este trabalho foi realizado com o objetivo de estudar a ação antimicrobiana do óleo essencial de Lippia gracilis, obtido de diferentes manejos de cultivo, no crescimento in vitro de $X$. campestris pv. viticola.

O trabalho foi conduzido no Laboratório de Fitopatologia da Universidade do Estado da Bahia (UNEB), no Departamento de Tecnologia e Ciências Sociais (DTCS), Campus III, Juazeiro, BA. O plantio e condução das mudas de lippia gracilis foram realizados no campo experimental de Bebedouro da Embrapa Semiárido, localizado Petrolina-PE. Os tratamentos constituíram de diferentes doses de adubação orgânica (esterco de animal - ovino/caprino curtido), com adubação ou não de 100 gramas do adubo mineral NPK para a formulação 15-9-20, com e sem irrigação (Tabela 1). As plantas foram irrigadas por gotejamento uma vez ao dia, durante quatro horas.

$\mathrm{O}$ experimento foi instalado em delineamento em blocos ao acaso em três repetições cada parcela constituindo-se de três plantas. A colheita de L. gracilis foi realizada após 120 dias de cultivo no período matutino. Após a coleta, as folhas de L. gracilis foram secas a $40 \pm$ 
Tabela 1. Procedencia de óleos essências de Lippia gracilis obtidos de diferentes manejo de cultivo da espécie, Embrapa Semiárido, Petrolina-PE.

\begin{tabular}{ccccc}
\hline Tratamento & Óleo Essencial & $\begin{array}{c}\text { Adubação orgânica } \\
\text { (t/ha) }\end{array}$ & $\begin{array}{c}\text { Adubação mineral (15-9-20) } \\
\text { Irrigação por gotejamento }\end{array}$ \\
\hline T1 & 0 & Presença & Presença \\
T2 & 01 & 0 & Ausência & Presença \\
T3 & 02 & 20 & Ausência & Presença \\
T4 & 03 & 40 & Presença & Presença \\
T5 & 04 & 40 & Ausência & Presença \\
T6 & 05 & 60 & Presença & Presença \\
T7 & 06 & 60 & Presença & Ausência \\
T8 & 07 & 60 & Ausência & Ausência \\
\hline
\end{tabular}

$1^{\circ} \mathrm{C}$ por quatro dias em estufa de secagem (Marconi MA 037). O óleo essencial foi obtido através da hidrodestilação do pó das folhas, em aparelho do tipo Clevenger.

As análises dos componentes dos óleos essenciais foram realizadas utilizando Cromatografia Gasosa acoplada à Espectrometria de Massas (CG-MS) e Cromatografia Gasosa acoplada com Detector por Ionização de Chama (CG-DIC) (9). A identificação dos constituintes foi realizada com base na comparação dos índices de retenção obtidos com os da literatura (1). Para o índice de retenção foi utilizada a equação de Vandendool \& Kratz (9) em relação a uma série homóloga de n-alcanos $\left(\mathrm{nC}_{9}-\mathrm{nC}_{18}\right)$.

Para estudo da atividade antimicrobiana dos óleos obtidos foi utilizado o isolado Xanthomonas campestris pv. viticola (Xcv3), proveniente da coleção de culturas bacterianas do Laboratório de Fitopatologia do DTCS/UNEB e se encontrava preservado em água destilada esterilizada (ADE) a temperatura de $25^{\circ} \mathrm{C}$. Sua e identificação foi confirmada por Polymerase Chain Reaction (PCR) com primers específicos (Xcv1F/Xcv3R).

Inicialmente testes qualitativos foram realizados a fim de selecionar uma dose mínima dos óleos essenciais de L. gracilis capazes de inibir o isolado Xcv3. O crescimento bacteriano foi transferido pelo método de estrias com alça de platina, em meio NYDA solidificado, contendo separadamente os óleos de L. gracilis diluídos em dimetilsulfóxido (DMSO) a $2 \%$ do volume total do meio de cultura. Foram utilizados oito óleos de L. gracilis obtidos de diferentes manejos de cultivo e cada óleo foi testado nas concentrações de 100, 200, 300 e $400 \mathrm{uL} \mathrm{L}^{-1}$. Cada tratamento foi repetido quatro vezes, sendo avaliada a presença e ausência de crescimento bacteriano na placa de Petri.

Os resultados obtidos neste experimento preliminar foram utilizados para estabelecimento das dosagens a serem utilizadas posteriormente. A ação inibidora foi avaliada utilizando-se suspensão bacteriana em água destilada esterilizada com uma concentração aproximadamente de $10^{8} \mathrm{UFC} \cdot \mathrm{mL}^{-1}\left(\mathrm{~A}_{580}=0,4\right)$. Alíquotas de $1 \mathrm{~mL}$ da suspensão bacteriana foram adicionadas em tubos de ensaio rosqueados contendo $10 \mathrm{~mL}$ de meio de NYDA sem ágar. Os tratamentos foram constituídos pelos oito óleos de $L$. gracilis obtidos de diferentes manejos do cultivo (Tabela 1), nas dosagens de 200, 250 e $300 \mathrm{uL} \mathrm{L}^{-1}$ (estabelecidos após experimento preliminar), testemunha absoluta e oxicloreto de cobre na dosagem de $32 \mathrm{mg} \cdot \mathrm{mL}^{-1}$ (produto utilizado pelos produtores da região para o controle do patógeno, em condições de campo). A absorbância das suspensões foi avaliada após 48 horas. Determinou-se a porcentagem de inibição do crescimento da bactéria pela aplicação da fórmula: $\mathrm{I}=$ $\left[\left(\mathrm{CB}_{\mathrm{c}}-\mathrm{CB}_{\mathrm{t}}\right) / \mathrm{CB}_{\mathrm{c}}\right] \times 100$, onde $\mathrm{I}=$ percentagem de inibição; $\mathrm{CB}_{\mathrm{c}}=$ crescimento bacteriano no controle; $\mathrm{CB}_{\mathrm{t}}=$ crescimento bacteriano no tratamento. $\mathrm{O}$ delineamento experimental foi inteiramente casualizado, constituído por 26 tratamentos, sendo oito óleos de L. gracilis obtidos de diferentes manejos de cultivo, três dosagens para cada óleo (200; 250 e $300 \mathrm{uL} \mathrm{L}^{-1}$ ), testemunha com o oxicloreto de cobre (controle padrão) e a testemunha absoluta. Cada tratamento constou de quatro repetições. As médias dos tratamentos foram comparadas pelo teste de Scott-Knott a 5\% de probabilidade pelo software ASSISTAT 7.5, sendo a testemunha absoluta comparada com a média geral dos tratamentos.

A análise da composição química dos óleos essenciais extraídos de L.gracilis por GC/MS e GC/FID, sob diferentes práticas agrícolas, revelou o carvacrol (73,9 a 77\%) como composto majoritário, além de timol (4,9 a 10,3\%), $\rho$-cimeno (1,68 a 3,19\%), Éter metil timol $(0,46$ a $2,36 \%)$ e o E-cariofileno (1,33 a 3,85) (Tabela 2). Resultados semelhantes foram encontrados por Albuquerque (2) para os principais componentes do óleo de L. gracilis: 10\% de timol, e 47\% de carvacrol, este último resultado um pouco diferente dos obtidos no presente estudo. Flutuações nas porcentagens dos compostos majoritários também foram verificados nos dados obtidos com relação às diferentes práticas agrícolas, a que as plantas de L. gracilis foram submetidas. Pode-se verificar, também que a maior porcentagem de timol (10,3\%) foi obtida no tratamento 06 , no qual as plantas de L. gracilis foram submetidas a $60 \mathrm{t} \mathrm{ha}^{-1}$ de adubação orgânica e também adubação química. Entretanto, Corrêa et al. (4), verificaram que a utilização de adubação orgânica embora tenha maximizado o rendimento de óleo essencial de Origanum vulgare L., diminuiu a produção de timol. Gomes et al. (5), relataram que a composição química do óleo de L. gracilis apresenta flutuações quantitativas dos componentes majoritários e essas variações, provavelmente, podem ser devidas a condições genéticas, em função do local e condições em que a planta foi cultivada.

No presente trabalho, nos testes para obtenção da concentração mínima inibitória para Xcv3, os dados obtidos mostraram diferenças na inibição do crescimento bacteriano para todos os óleos testados: nas concentrações de 300 e 400 uL.L ${ }^{-1}$ houve inibição total do crescimento bacteriano; na dosagem de 200 uL.L ${ }^{-1}$ houve inibição total do crescimento bacteriano apenas quando se utilizaram os óleos referentes aos tratamentos T1, T5 e T6 e na dosagem de 100 uL.L ${ }^{1}$, não houve inibição do crescimento bacteriano (Tabela 3). Portanto, de acordo com esses resultados, dosagens de 200, 250 e 300 uL.L-1, foram testadas no segundo experimento.

Diferenças significativas para a porcentagem de inibição do crescimento do patógeno foram observadas para todos os óleos de L. gracilis, estudados, apresentando valores entre $62,67 \%$ a $96,50 \%$. Os tratamentos T1 a T3, T6 e T12 a T18 proporcionaram as maiores porcentagens de inibição de Xcv3, variando de $96,50 \%$ (T13) a 90,80\% (T17), não diferindo estatisticamente entre si $(\mathrm{P}=0,05)$. Todos os tratamentos testados apresentaram porcentagens de inibição maiores 
Tabela 2. Composição química dos óleos essenciais de L. gracilis caracterizados por GC/MS ${ }^{1}$ e GC/FID², sob diferentes práticas agrícolas.

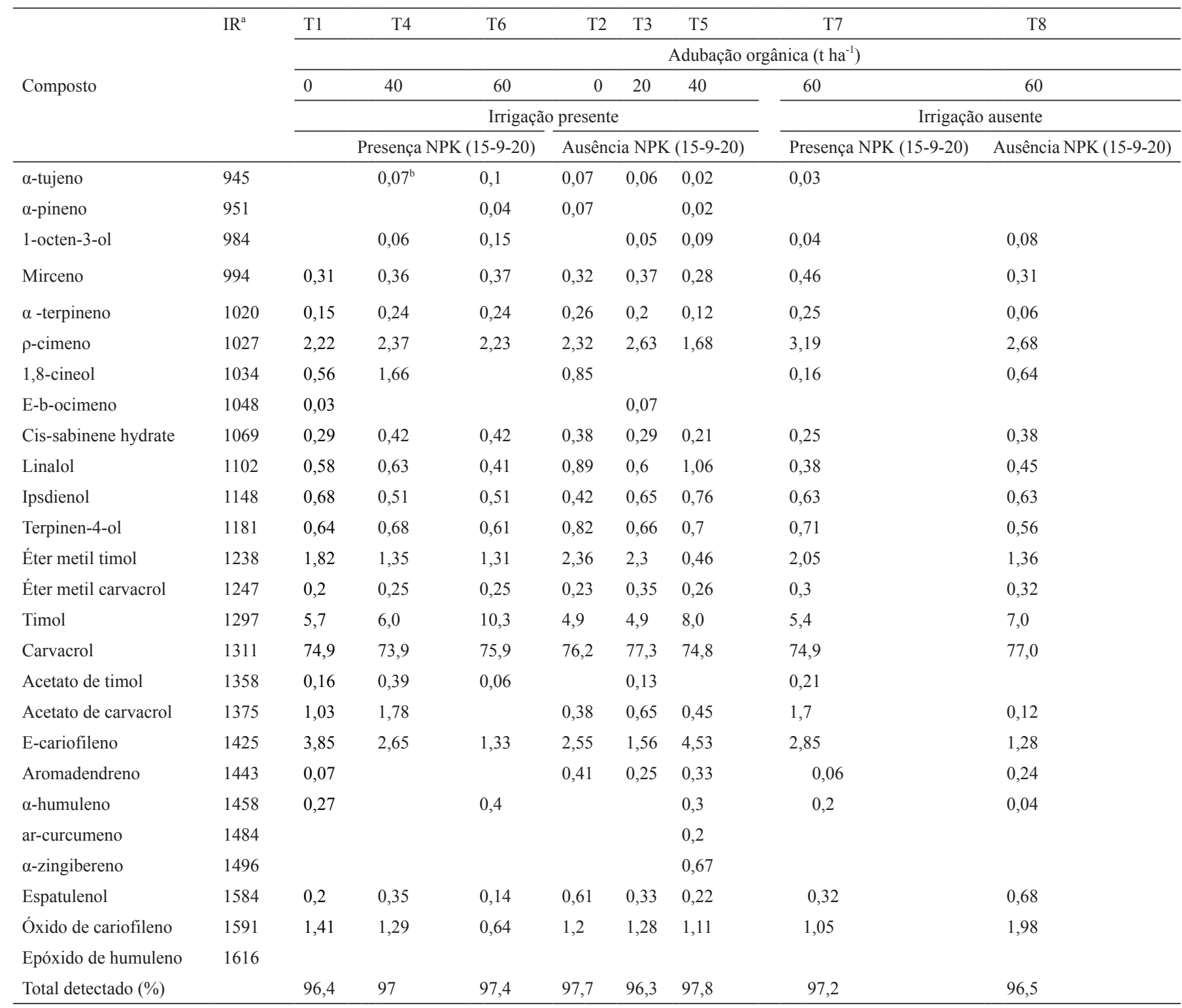

${ }^{1}$ Técnica analítica de Cromatografia Gasosa Acoplada à Espectrometria de Massas

${ }^{2}$ Técnica analítica de Cromatografia Gasosa/Detector por Ionização em Chama

a Índice de retenção calculado utilizando a equação de Vandendool e Kratz (1963) em relação a uma série homóloga de $n$-alcanos ( $n$ C9- $n$ C18).

${ }^{\mathrm{b}}$ Valores do conteúdo dos compostos obtidos pela média de três diferentes determinações obtidas por GC/MS e GC/FID. Traços indicam que o composto não foi encontrado.

que a proporcionada pelo oxicloreto de cobre $(46,6 \%)$, produto comercial utilizado pelos produtores da região do Submédio São Francisco, para manejo do cancro bacteriano da videira, em condições de campo (Tabela 04).

Os ótimos resultados obtidos neste trabalho, com alta porcentagem de inibição do crescimento de Xcv, bactéria Gram-negativa, podem estar relacionados com as observações de Knowles et al. (6). De acordo com esses autores o carvacrol e o timol podem desintegrar a membrana externa de bactérias Gram-negativas, liberando lipopolissacarídeos e, consequentemente, gerando alterações na permeabilidade da membrana plasmática, o que resulta na morte da célula bacteriana. Ainda, segundo Burt (3), existe interação entre o carvacrol e o timol, que resulta em uma ação sinérgica entre eles potencializando a ação de ambos frente ao controle das células bacterianas e o óleo de $L$. gracilis apresenta o carvacrol e o timol como componentes majoritários.

O óleo essencial e extrato de pimenta-longa (Piper aduncum) e extrato etanólico de comigo-ninguém-pode (Dieffenbachia picta) também foram eficientes na inibição apresentam capacidade de inibição do crescimento de Ralstonia solanacearum (10). Além disso, de acordo com Amorim et al. (4), o óleo essencial de citronela (Cymbopogon nardus), de cravo-da-índia (Caryophyllus aromaticum) e de gengibre (Zingiber officinale) foram capazes de inibir o crescimento de $R$. solanacearum in vitro em todas as concentrações testadas, sendo o óleo de cintronela capaz de controlar a incidência da doença em 100\%, quando testado em mudas de bananeira.

Conforme já citado anteriormente, no presente trabalho todos 
Tabela 3: Seleção da concentração mínima inibitória dos óleos essenciais de Lippia gracilis, obtidos de diferentes manejos de cultivo, sobre crescimento bacteriano do isolado Xcv3. Juazeiro-BA, 2013.

\begin{tabular}{ccccc}
\hline \multicolumn{5}{c}{ Dosagem (uL.L - 1 ) } \\
\hline Óleo & 100 & 200 & 300 & 400 \\
T1 & SI2 & IT3 & IT & IT \\
T2 & SI & IP4 & IT & IT \\
T3 & SI & IP & IT & IT \\
T4 & SI & IP & IT & IT \\
T5 & SI & IT & IT & IT \\
T6 & SI & IT & IT & IT \\
T7 & SI & IP & IT & IT \\
T8 & SI & IP & IT & IT \\
ADE & SI & SI & SI & SI \\
\hline
\end{tabular}

${ }^{1}$ Dosagem utilizada do óleo essencial de Lippia gracilis.

${ }^{2}$ SI - Sem inibição do crescimento bacteriano do isolado Xcv3

${ }^{3}$ IT - Inibição total do crescimento bacteriano do isolado Xcv3 .

${ }^{4}$ IP - Inibição parcial do crescimento bacteriano do isolado Xcv3

${ }^{5} \mathrm{ADE}$ - Água Destilada Esterilizada

Tabela 4. Porcentagem de inibição do crescimento in vitro de Xanthomonas campestris pv. viticola, cultivada em meio líquido (NYD) com diferentes concentrações de óleo essencial de Lippia gracilis obtidos de distintos manejos de cultivo, Juazeiro,BA, 2013.

\begin{tabular}{|c|c|c|c|}
\hline Tratamento & Óleo essencial $^{1}$ & $\begin{array}{c}\text { Concentração } \\
\left(\text { uL.L } \mathbf{L}^{-1}\right)^{2}\end{array}$ & $\begin{array}{c}\text { Porcentagem de } \\
\text { inibição (\%) }\end{array}$ \\
\hline $\mathrm{T} 1$ & 01 & 200 & $93,67 \mathrm{a}$ \\
\hline $\mathrm{T} 2$ & 01 & 250 & $93,70 \mathrm{a}$ \\
\hline $\mathrm{T} 3$ & 01 & 300 & $94,75 \mathrm{a}$ \\
\hline $\mathrm{T} 4$ & 02 & 200 & $62,67 \mathrm{~d}$ \\
\hline $\mathrm{T} 5$ & 02 & 250 & $62,67 \mathrm{~d}$ \\
\hline $\mathrm{T} 6$ & 02 & 300 & $91,20 \mathrm{a}$ \\
\hline $\mathrm{T} 7$ & 03 & 200 & $81,35 \mathrm{c}$ \\
\hline $\mathrm{T} 8$ & 03 & 250 & $80,62 \mathrm{c}$ \\
\hline T9 & 03 & 300 & $81,60 \mathrm{c}$ \\
\hline $\mathrm{T} 10$ & 04 & 200 & $85,20 \mathrm{c}$ \\
\hline $\mathrm{T} 11$ & 04 & 250 & $86,25 \mathrm{~b}$ \\
\hline $\mathrm{T} 12$ & 04 & 300 & 94,37 a \\
\hline $\mathrm{T} 13$ & 05 & 200 & $96,50 \mathrm{a}$ \\
\hline $\mathrm{T} 14$ & 05 & 250 & 91,17 a \\
\hline $\mathrm{T} 15$ & 05 & 300 & $94,40 \mathrm{a}$ \\
\hline $\mathrm{T} 16$ & 06 & 200 & $92,97 \mathrm{a}$ \\
\hline $\mathrm{T} 17$ & 06 & 250 & $90,80 \mathrm{a}$ \\
\hline $\mathrm{T} 18$ & 06 & 300 & $94,02 \mathrm{a}$ \\
\hline T19 & 07 & 200 & $83,07 \mathrm{c}$ \\
\hline $\mathrm{T} 20$ & 07 & 250 & $86,95 \mathrm{~b}$ \\
\hline $\mathrm{T} 21$ & 07 & 300 & $86,95 \mathrm{~b}$ \\
\hline $\mathrm{T} 22$ & 08 & 200 & $78,87 \mathrm{c}$ \\
\hline $\mathrm{T} 23$ & 08 & 250 & $81,70 \mathrm{c}$ \\
\hline $\mathrm{T} 24$ & 08 & 300 & $79,95 \mathrm{c}$ \\
\hline $\mathrm{T} 25$ & $\begin{array}{l}\text { Oxicloreto de } \\
\text { cobre }\end{array}$ & $32 \mathrm{mg} \cdot \mathrm{ml}^{-1}$ & $49,6 \mathrm{e}$ \\
\hline \multirow[t]{2}{*}{$\mathrm{T} 26$} & $\begin{array}{c}\text { Testemunha } \\
\text { absoluta }\end{array}$ & ---- & $0,0 \mathrm{f}$ \\
\hline & $\mathrm{CV} \%$ & 4,90 & \\
\hline
\end{tabular}

${ }^{1}$ Tratamento do óleo essencial extraído de Lippia gracilis em diferentes manejos de cultivo. ${ }^{2}$ Concentração do óleo essencial de Lippia gracilis no meio de cultura NYD.

$\mathrm{CV} \%$ - coeficiente de variação os óleos testados proporcionaram uma porcentagem de inibição do crescimento bacteriano significativamente superior ao oxicloreto de cobre, produto padrão utilizado no campo para o controle de Xcv, que inibiu apenas 49,6\%. Segundo Marques et al. (7), os isolados brasileiros de Xcv diferem em sua sensibilidade aos produtos a base de cobre, apresentando estirpes naturalmente mais tolerantes. Os óleos de plantas conferem menor risco em promover resistência microbiana, já que são misturas de vários compostos que apresentam diferentes ações aos patógenos.

O uso do óleo essencial de L. gracilis mostrou potencial para inibir o crescimento de Xcv3, in vitro, podendo constituir uma alternativa no manejo integrado do cancro bacteriano da videira. Entretanto, pesquisas em condições de casa de vegetação e de campo devem ser realizadas para comprovação dos resultados obtidos.

\section{REFERÊNCIAS}

1. Adams, R.P. Identification of essential oil components by gas chromatograpy/mass spectroscopy, 4 th ed. Illinois, Allured, 2007.804p.

2. Albuquerque, C.C. Ação do óleo essencial L. gracilis Schauer sobre fungos contaminantes do ar e bactérias endofíticas cultivadas de helicônias in vitro. 2005. $85 \mathrm{f}$. Tese (Doutorado em Botânica)-Universidade Federal Rural de Pernambuco, Recife.

3. Burt, S. A. Antibacterial activity of essential oils: potential aplication in food. 2007. $136 \mathrm{f}$. Ph. D. Thesis, Institute for Rish Assessment Sciences, Utrecht University. Utrecht.

4. Corrêa, R. M.; Pinto, J. E. B. P.; Reis, E. S.; Costa, L. C. B.; Alves, P. B.; Niculan, E.S.; Brant, R.S. Adubação orgânica na produção de biomassa de plantas, teor e qualidade de óleo essencial de orégano (Origanum vulgare L.) em cultivo protegido. Revista Brasileira de Plantas Medicinais, Botucatu, v.12, n.1, p.80-89, 2010.

4. Gomes, S. V. F.; Nogueira, P. C. L.; Moraes, V. R. S. Aspestos químicos e biológicos do gênero Lippia enfatizando Lippia gracilis Schauer. Eclética Química, São Paulo, v. 36, n. 1, p. 64-77. 2011.

5. Knowles, J. R.; Roller, S.; Murray, D. B.; Naidu, A. S. Antimicroe bial action of carvacrol at different stages of dual-species biofilm development by Staphylococcus aureus and Salmonella enterica serovar Typhimurium. Applied and Enviromental Microbiology. Washington, v. 71, n. 2, p. 797-803. 2005.

6. Marques, E.; Uesugi, C. H.; Ferreira, M. A. S. V. Sensitivity to cooper in Xanthomonas campestris pv. viticola. Tropical Plant Pathology, Brasília-DF, v.34, n.6, p. 406-411, 2009.

7. Neves, I. A. ; Oliveira, J. C. S. ; Camara, C. A. G. ; Schwartz, M. O. E. Chemical composition of the leaf oils of Lippia gracilis Schauer from two localities of Pernambuco. The Journal of Essential Oil Research, Carol Stream, v. 20, n. 2, p. 157-160, 2008.

8. Vandendool, H.; Kratz, J.D.J. A generalization of the retention index system including linear temperature programmed gas-liquid partition chromatography. Journal of Chromatography, Amsterdam, v. 11, p. 463-471. 1963.

9. Véras, S. M.; Kaoru, Y.; Rocha, S. N.; Pinheiro, C. C. Extratos e óleos voláteis vegetais com potencial para controle de Ralstonia solanacearum. Fitopatologia Brasileira, Brasília, DF, v.27, supl., p. 5-72, 2002. 